in crop size, not the variation in the ratio of the crop size to the state estimate.

The results of the model show the effect of the May weather. The signs and size of the two weather coefficients indicate that the weather correction is largest (in a negative direction) for a value of 97 cooling degree days, weather that is below average (since May weather averages about 130 cooling degree days). During the 10 years studied, May temperatures varied from a minimum of 15 cooling degree days in 1977 to a maximum of 220 cooling degree days in 1984. In years when the weather is particularly warm (over 172 cooling degree days), the correction is a positive one. Because of the parabolic form of the correction, the state estimate is unbiased for May cooling degree values of 21 and 172 . At these values, the weather adjustment model would give exactly the same estimate as the state model. The state model therefore will work well in a range around these two cooling degree day values, will be biased toward overestimation in between, and will be biased toward underestimation for values of more than 172 cooling degree days (fig. 2).

The correction improves the crop forecasts noticeably. For the past four years, this model has been within 1 percent of the actual crop (table 1).

\begin{tabular}{cccc}
\multicolumn{4}{c}{ TABLE 1. Model results } \\
\hline \hline Year & $\begin{array}{c}\text { Actual } \\
\text { crop }\end{array}$ & $\begin{array}{c}\text { State } \\
\text { estimate }\end{array}$ & $\begin{array}{c}\text { Weather } \\
\text { model }\end{array}$ \\
\hline \multicolumn{4}{c}{---meat pounds (millions)---- } \\
1976 & 284 & 280 & 266.4 \\
1977 & 313 & 310 & 313.2 \\
1978 & 181 & 205 & 194.9 \\
1979 & 376 & 350 & 347.9 \\
1980 & 322 & 340 & 318.6 \\
1981 & 408 & 450 & 437.9 \\
1982 & 347 & 365 & 348.9 \\
1983 & 242 & 250 & 242.6 \\
1984 & 587 & 520 & 592.1 \\
1985 & 462 & 495 & 462.1
\end{tabular}

NOTE: The model is as follows:

$Y=1.0431-0.0022722 X+0.00001175 X^{2}$

$$
\begin{array}{lll}
(16.82) & (-2.28) \quad(2.95)
\end{array}
$$$$
\text { MSE }=0.002792 \quad R^{2}=98.1 \% \quad n=10
$$

$Y=$ actual crop/state estimate

$X=$ May cooling degree days

The numbers in parentheses are the t-ratios.

\section{Conclusions}

The model developed here predicts the almond crop more accurately than does the state estimate. Because it is based on a correction of the state estimate for May weather, it can be computed immediately following the state estimate in July. The state estimate is by no means obsolete, however, since it forms the basis for this model.

Jeffrey Dorfman is a student and Dale $M$. Heien is Associate Professor in the Department of Agricul tural Economics, University of California, Davis The authors wish to acknowledge the help of the Callfornia Almond Growers Exchange.
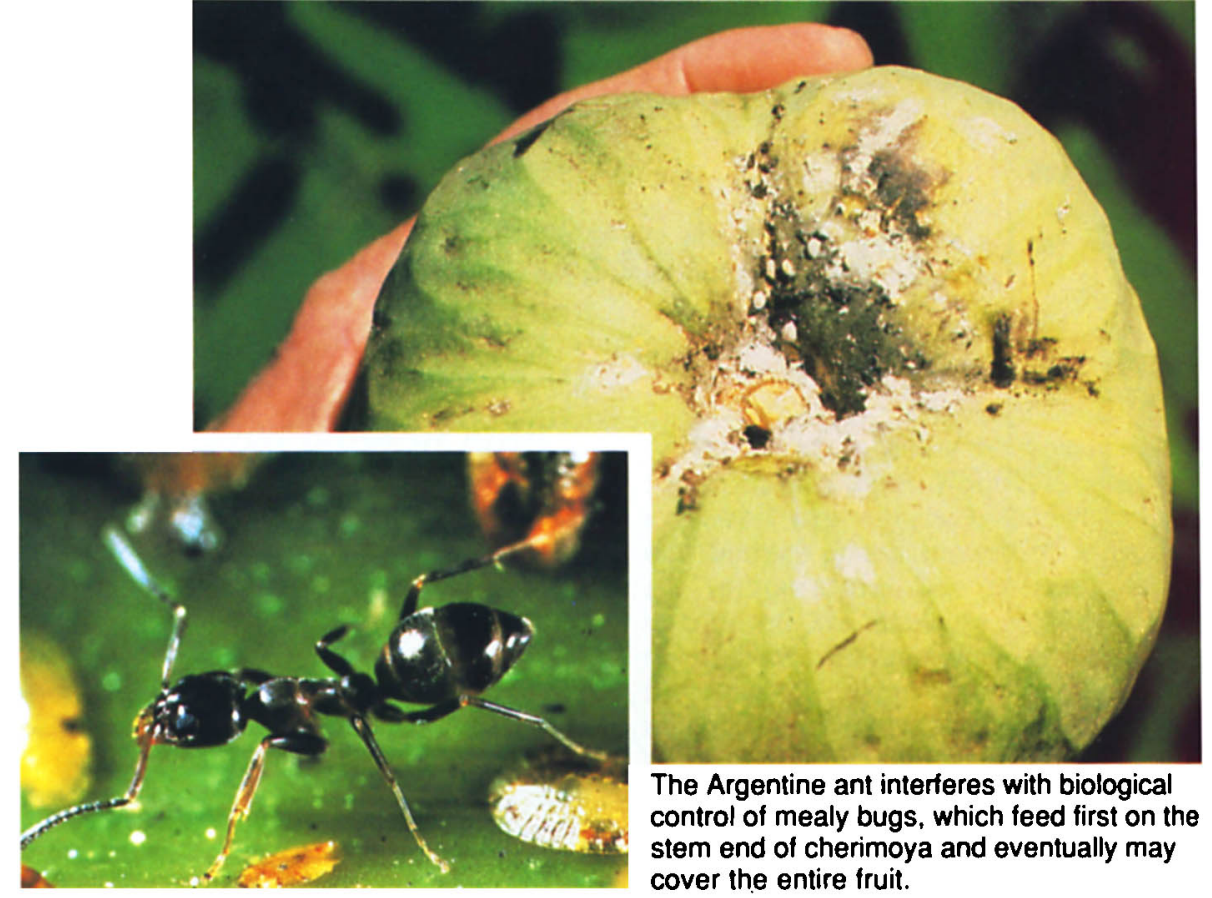

The Argentine ant interferes with biological control of mealy bugs, which feed first on the stem end of cherimoya and eventually may cover the entire fruit.

\title{
Argentine ant management in cherimoyas
}

Phil A. Phillips $\square$ Ronald S. Bekey

$T_{\text {he }}$ he hexagonally faceted fruit known as the cherimoya is native to the tropical mountain valleys of Ecuador and Peru. Spanish explorers introduced the fruit, Annona cherimola, into Spain, and from there it spread to other Mediterranean countries. It is now found in nearly all semitropical and subtropical climates worldwide.

The first known successful introduction into the United States occurred in California in 1871, when Judge R.B. Ord of Santa Barbara obtained some seed from Mexico. The state's first commercial planting was by Jacob Miller just before the turn of the century, near what is now the center of Hollywood. Commercial acreage in California today is about $\mathbf{2 0 0}$ acres, primarily in Santa Barbara, Ventura, and San Diego counties.

A similar fruit, the atimoya (an $A n$ nona hybrid) is grown in Florida. Small commercial cherimoya plantings also exist in Argentina, Spain, Egypt, South Africa, and Australia.

The cherimoya is actually a multiple fruit, similar to a pineapple in structure. Each hexagonal shield is a separate fruit that has fused with its neighbor, forming a heart-shaped ball. The flesh is butterywhite with an exotic pineapple-banana flavor. The trees are semideciduous, dropping their leaves in late April or early May in southern California. Blooming begins at the same time as the new leaves are produced, just after leaf drop, and may continue for several months. Fruits require about eight months to mature, so

\author{
George E. Goodall
}

the harvest period also extends for several months.

\section{Pests}

The cherimoya is relatively resistant to the common rootknot nemotode, Meloidogyne spp., and to avocado root rot, $P h y-$ tophthora cinnamomi. Oak root fungus, Armillarea mellea, and a fruit-spot disease that has not yet been identified have been reported in some orchards.

Cherimoyas grown in California have been free of some of the serious insect pests that occur elsewhere, including fruit flies, seed chalcids, and borers. Since 1945 , however, mealy bug infestations have been reported. As is true in other subtropical crops, such infestations can become economically devastating when biological control is disrupted by honeydew-seeking ants.

In Santa Barbara and Ventura counties, the Argentine ant, Iridomyrmex humilis, is the species most commonly involved. This ant, with its highly aggressive nature, displaces other less noxious ant species in the orchard and then interferes with biological control agents associated with honeydew-producing mealy bugs.

The long-tailed mealy bug, Pseudococcus adonidum, is the major insect threat to fruit quality. These mealy bugs usually attack the stem end of the fruit first and eventually cover the entire fruit. Infestations also may begin at contact points between fruits or between leaves and fruit. A sooty mold fungus, Cladosporium sp., 
grows on the mealy bugs' honeydew exudate on the fruit surface. Since these surface contaminants are not easy to remove from the fruit's fragile thin skin, the fruit become unmarketable.

The long-tailed mealy bug is generally under good biological control in cherimoya orchards where ants are not foraging in the trees. A practical, effective management strategy is needed, however, in orchards with ant-aggravated mealy bug problems. We therefore conducted an experiment in 1984 to find an appropriate control.

\section{Ant-management experiment}

The test site was a 5-acre block of 'White' cherimoyas in Carpenteria (Santa Barbara County) with a history of mealy bug and ant problems. Before the experiment, the trees' skirts were pruned above ground level so that the ants' only access to the canopies was via the trunks. After pruning, we tested several methods of control, including physical barriers, baits, and spot insecticide treatments.

The treatments were (1) a sticky band barrier of Tangletrap aerosol sprayed in a 3 -inch width around the trunk, (2) a bait station filled with a sugar/carboxymethylcellulose bait and Amdro (registered only for control of imported fire ant outside California), and (3) a spot application to the base of the trunk and the adjacent 12 inches of soil using a 2 percent solution of Lorsban 4E (chlorpyrifos; not currently registered for this use). The three treatments plus an untreated check were arranged in a randomized complete block design, and each treatment was replicat- ed four times with three trees per replicate.

After surveying the Argentine ants on May 10, 1984, we applied the treatments on May 11. Posttreatment surveys conducted weekly through September recorded ant activity as the number of ants per minute passing a point on the trunk. Trail intensities were rated on a scale of 0 to 5 , ranging from no ants to 51-100 ants per minute (see table 1).

We rated mealy bug infestations on October 10,1984 , by randomly selecting 40 fruit from each three-tree replicate and assigning the infestation level on each fruit to one of four categories from none to more than half of the surface area infested (table 1). Because of the low level of mealy bugs relative to our experimental needs, we totaled the ratings for all $\mathbf{4 0}$ fruit within each replicate for analysis.

\section{Results}

Argentine ant activity in the untreated plots dropped during June and July, then increased through October (fig. 1). Among the treatments, the sticky band controlled ants the most effectively (table 1), but it required several reapplications. The sticky band became weathered and coated with wind-blown debris, making it necessary to remix the old coating on the trunk or to add a fresh coating of Tangletrap. Cracking of the bark beneath the sticky band was also visible, although there was no apparent reduction in tree vigor or yield.

The Lorsban $4 \mathrm{E}$ spot treatment was the next most effective, while the Amdro bait was not significantly different from the untreated check. The Amdro stations,

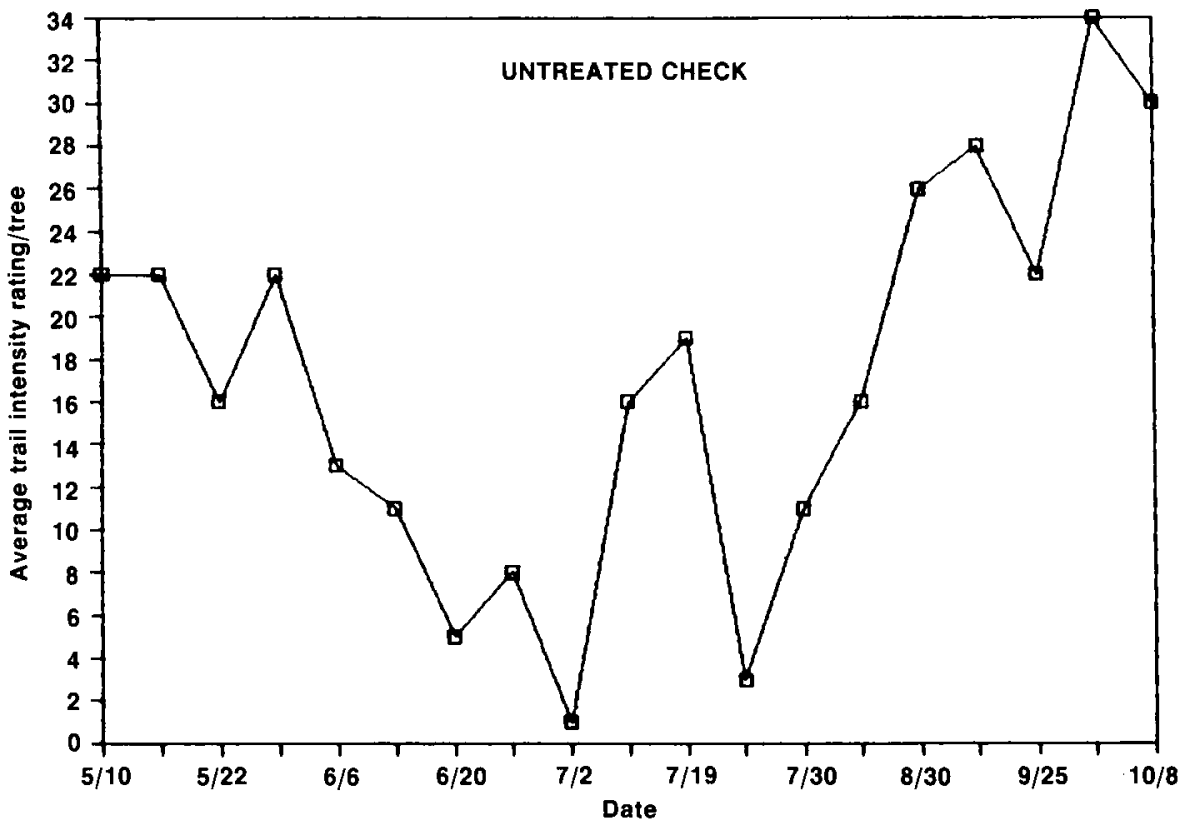

Fig. 1. In untreated plots, Argentine ant activity decreased in June and July, then increased.
TABLE 1. Effect of three treatments on Argentine ant and long-tailed mealy bug infestations in a cherimoya orchard

\begin{tabular}{lcc}
\hline \hline Treatment & $\begin{array}{c}\text { Ant trail } \\
\text { intensity } \\
\text { rating* }^{*}\end{array}$ & $\begin{array}{c}\text { Mealy bug } \\
\text { infestation } \\
\text { ratingt }\end{array}$ \\
\hline $\begin{array}{c}\text { Untreated } \\
\text { check }\end{array}$ & $1.425 \mathrm{a}$ & $0.690 \mathrm{a}$ \\
Amdro bait & $1.390 \mathrm{a}$ & $0.500 \mathrm{a}$ \\
Lorsban & $1.004 \mathrm{~b}$ & $0.330 \mathrm{a}$ \\
Sticky band & $0.522 \mathrm{c}$ & $0.120 \mathrm{a}$ \\
\hline
\end{tabular}

NOTE: Treatments followed by different letters are significantly different by Duncan's Multiple Range Test, $5 \%$ level.

Mean rating per tree of 19 sampling dates. Scale: $0=$ no ants, $1=<1$ ant $/ \mathrm{min} ., 2=1-5$ ants $/ \mathrm{min} ., 3=6-25$ ants $/$ min., $4=26-50$ ants $/$ min., $5=51-100$ ants $/ \mathrm{min}$

$\dagger$ Mean of rating totals for each 40-fruit replicate on Oct. 10,1984 . Scale: $0=$ no mealy bugs, $1=$ up to 10 mealy bugs, $2=$ up to half of fruit surface area infested, $3=$ over half of surface area infested.

like the Tangletrap treatment, required continual maintenance. The bait container had to be refilled at about four-week intervals throughout the season.

Mealy bug infestation levels (average of rating totals for each 40-fruit replicate) five months after treatment were closely related to the average ant infestation level (average number of ants per minute) over all dates sampled $(\mathrm{R}=.95)$. Levels were greatest in the check plot and least in the sticky band treatment. The Lorsban spot treatment had the next lowest mealy bug infestation level.

\section{Conclusions}

The Lorsban $4 \mathrm{E}$ spot treatment (not presently registered for this use in California) at the junction of tree trunk and soil provided the best combination of efficacy and practicality in our study. It controlled Argentine art populations more effectively and resulted in a lower buildup of mealy bugs than did Amdro bait, and it required considerably less labor than did the other two treatments. Because this treatment only prevented access to the tree trunks, skirt pruning was also important to keep ants from infesting the trees via foliage touching the ground. We judged the sticky band treatment, while most effective in our trial, to be impractical because of the extensive labor involved in reapplying it at frequent intervals.

Lorsban $4 \mathrm{E}$ is currently going through the IR-4 minor crops pesticide registration process for cherimoyas, pineapple guavas (feijoas), and sapotes.

Phil A. Phillips is Area Integrated Pest Mangement Advisor, Cooperative Extension, Ventura County, Ronald S. Bekey is Farm Advisor, Ventura and Santa Barbara counties; and George E. Goodall is Farm Advisor, Santa Barbara County. The authors thank the Brown family in Carpenteria for the use of their the Brown family in Carpenteria for the use orchard, Dr. Lyle Gaston, Division of Toxicology University of California, Riverside, for donation of the Amdro bait; and Tak Iwata, Department of Entomology, UC Riverside, for chlorpyrifos residue analysis. They also thank Jerry Davidson, Agricultural Commissioner's Office, Santa Barbara County, and Mary Fergusen and Harold Alford, IR-4 program, for their valuable suggestions and cooperation. 